\title{
The Coseismic Fault Weakening Processes Inferred from Frictional and Transport Properties of Fault Rocks, TCDP
}

\author{
by Hiroki Sone, Hiroyuki Noda, and Toshihiko Shimamoto
}

\author{
doi:10.2204/iodp.sd.s01.06.2007
}

Faults weaken during coseismic slip, and many factors affect the weakening process. Among these are the frictional properties and permeability of fault-consisting materials. The Taiwan Chelungpu-fault Drilling Project recovered cores from $500 \mathrm{~m}$ to $2000 \mathrm{~m}$ depth, penetrating several distinct major fault planes that are likely the slip planes from the 1999 Chi-Chi Earthquake (Ma et al., 2006). We measured transport properties of fault rocks and conducted highvelocity friction experiments using drill core samples from two fault zones at $1111 \mathrm{~m}$ and $1153 \mathrm{~m}$ depths (FZA1111 and FZA1153), and attempted to reconstruct the coseismic fault weakening processes due to the change in frictional coefficient and the effect of thermal pressurization (Sibson, 1973).

Gas permeability of the fault rock samples were measured in a tri-axial apparatus using a steady-flow method with nitrogen gas for several pore pressure gradients $(0.1-2.0$ $\mathrm{MPa}$ ) at effective pressures up to $140 \mathrm{MPa}$. Results show that permeability values range between $10-14$ and $10-18 \mathrm{~m}^{2}$, and also that permeability is 1-2 orders lower in FZA1111 than in FZA1153. Data under various pore pressure gradients allowed us to subtract the Klinkenberg effect for gas permeability, and thus we estimate the water permeability to be several factors lower. High-velocity frictional experiments were conducted at a normal stress of $0.7 \mathrm{MPa}$, using a highvelocity ring-shear friction apparatus. Velocity was continuously controlled so that the velocity history reproduces the coseismic slip history derived from a study based on waveform inversions (Ji et al., 2003). The frictional coefficient decreased with acceleration and slip down to 0.1-0.2, and then recovered as the fault slip decelerated to a level below its initial friction. This indicates that a velocity weakening behavior was observed as the fault weakened by slip weakening as well.

The coseismic fault weakening process was modeled using these laboratory-derived physical properties based on equations of thermal pressurization by Lachenbruch (1980). The overall features of the resulting fault strength curve matched well with fault traction curves from inversion studies (see Fig. 1). Also the introduction of thermal pressurization seemed to enhance the difference between laboratory- and inversionderived curves, in terms of both stress drop and weakening distance, Dc. However, temporal resolutions of waveform inversions are limited by the frequencies of the waveforms used, and thus the stress drops and weakening distances are not directly comparable. Recent studies show that inversion results preserve information on the seismological fracture energies accurately, but not the stress drop values and weakening distances (Guatteri and Spudich, 2000). We determined the apparent seismological fracture energies from the laboratory derived curve, but the physical interpretation of such manipulation was indefinite. It is important to understand which features are comparable, and which are not, between the laboratory-determined fault strength curves and traction curves derived from seismological studies.

\section{References}

Guatteri, M. and Spudich, P., 2000. What can strong-motion data tell us about slip-weakening fault-friction law? Bull. Seismol. Soc. Am., 90:98-116, doi:10.1785/0119990053.

Ji, C., Helmberger, D. V., Wald, D. J. and Ma, K. F., 2003 Slip history and dynamic implications of the 1999 Chi-Chi, Taiwan, earthquake. J. Geophys. Res. 108(B9): 2412, doi:10.1029/ 2002JB001764.

Lachenbruch, A.H., 1980. Frictional heating, fluid pressure, and the resistance to fault motion. J. Geophys. Res., 85:6097-6112.

Ma, K.F., Tanaka, H., Song, S.R., Wang, C.Y., Hung, J.H., Tsai, Y.B., Mori, J., Song, Y.F., Yeh, E.C., Soh, W., Sone, H., Kuo, L.W., and Wu, H.Y., 2006. Slip zone and energetics of a large earthquake from the Taiwan Chelungpu-fault drilling project.

Nature, 444:473-476, doi: 10.1038.

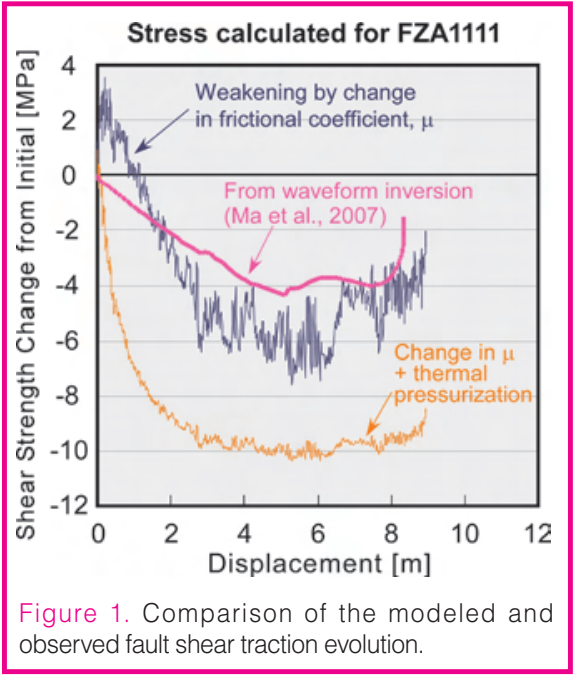

Sibson, R.H., 1973. Interactions between temperature and pore fluid pressure during an earthquake faulting and a mechanism for partial or total stress relief. Nature, 243:6668.

\section{Authors}

Hiroki Sone, Hiroyuki Noda, and Toshihiko Shimamoto, Department of Geology and Mineralogy, Division of Earth and Planetary Sciences, Graduate School of Science, Kyoto University, Kitashirakawa Oiwakecho, Sakyo-ku, Kyoto, 606-8502, Japan. e-mail: shima@ kueps.kyoto-u.ac.jp 